\title{
Development of objective indicators for quantitative analysis of sodium intake: the sodium to potassium ratio of second-void urine is correlated with 24-hour urinary sodium excretion
}

\author{
Jung Gon Kim ${ }^{1 *}$, Sang-Woong Han ${ }^{2 *}$, Joo Hark $\mathrm{Yi}^{2}$, Hyeong Cheon Park ${ }^{3}$ and Sang Youb Han ${ }^{1 \S}$ \\ ${ }^{1}$ Department of Internal Medicine, Inje University Ilsan-Paik Hospital, Gyeonggi 10380, Korea \\ ${ }^{2}$ Department of Internal Medicine, Hanyang University Guri Hospital, Gyeonggi 11923, Korea \\ ${ }^{3}$ Department of Internal Medicine, Yonsei University Gangnam Hospital, Seoul 06273, Korea
}

BACKGROUND/OBJECTIVES: To date, sodium intake has been evaluated based on spot urine instead of 24-hour (hr) urine collection. Nevertheless, the optimal method for assessing daily sodium intake remains unclear.

SUBJECTS/METHODS: Fifteen male (age $32.7 \pm 6.5$ years) participants were offered 3 meals with a total of 9-10 g salt over 24 hours, and 24-hr urine was collected from the second-void urine of the first day to the first-void urine of the second day. Twenty-four-hr urinary sodium (24UNa) was estimated using Tanaka's equation and the Korean formula, and spot urine $\mathrm{Na}$, potassium $(\mathrm{K})$, chloride $(\mathrm{Cl})$, urea nitrogen $(\mathrm{UN})$, creatinine $(\mathrm{Cr})$, specific gravity $(\mathrm{SG})$ and osmolality (Osm) were measured. The ratios of urinary $\mathrm{Na}$ to other parameters were calculated, and correlations with total measured 24UNa were identified. RESULTS: Average 24-hr urine volume was 1,403 $\pm 475 \mathrm{~mL}$, and measured 24UNa was $143.9 \pm 42.1 \mathrm{mEq}$ (range, 87.1-239.4 mEq). Measured 24UNa was significantly correlated with urinary Na/UN $(r=0.560, P<0.01)$, urinary Na/Osm $(r=0.510, P<0.01)$, urinary $\mathrm{Na} / \mathrm{Cr}(r=0.392, P<0.01)$, urinary Na/K $(r=0.290, P<0.01)$, 24UNa estimated using Tanaka's equation $(r=0.452, P<0.01)$ and the Korean formula $(r=0.414, P<0.01)$, age $(r=0.548, P<0.01)$, weight $(r=0.497, P<0.01)$, and height $(r=0.393, P<0.01)$ in all spot urine samples. Estimated 24UNa based on the second-void spot urine of the first day tended to be more closely correlated with measured 24UNa than were estimates from the other spot urine samples. The significant parameters correlated with the second-void urine of the first day were urinary Na/K $(r=0.647, P<0.01)$, urinary $\mathrm{Na} / \mathrm{Cr}(r=0.558, P<0.05)$, and estimated 24UNa using Tanaka's equation $(r=0.616, P<0.05)$ and the Korean formula $(r=0.588, P<0.05)$.

CONCLUSIONS: Second-void urine is more reliable than first-void urine for estimating $24 \mathrm{UNa}$. Urinary $\mathrm{Na} / \mathrm{K}$ in the second-void urine on the first day is significantly correlated with $24 \mathrm{UNa}$. Further studies are needed to establish the most reliable index and the optimal time of urine sampling for predicting $24 \mathrm{UNa}$.

Nutrition Research and Practice 2020;14(1):25-31; https://doi.org/10.4162/nrp.2020.14.1.25; pISSN 1976-1457 elSSN 2005-6168

Keywords: Dietary sodium; sodium excretion; urine collection

\section{INTRODUCTION}

Assessing dietary sodium intake is very important in public health care. Sodium intake, a modifiable risk factor, is associated with hypertension and kidney disease, and is ultimately related to cardiovascular deaths [1]. Limiting dietary salt consumption is known to be beneficial for preventing the progression of cardiovascular and kidney disease [2,3]. Currently, even healthy adults are encouraged to reduce dietary sodium [4,5].

Twenty-four-hour (hr) urinary sodium ( $\mathrm{Na} ; 24 \mathrm{UNa}$ ) is the gold standard for estimating daily sodium intake [6] and is a reliable method for monitoring and assessing sodium intake for salt restriction in population studies $[7,8]$. It can also be used for objectively evaluating diuretic response, dietary compliance, blood pressure control and risk of cardiovascular disease among patients with edematous or hypertensive diseases such as liver cirrhosis [9,10], heart failure [11] and chronic kidney disease $[12,13]$. However, obtaining 24-hr urine from outpatients is difficult and time-consuming, and the results are often imprecise due to inadequate urine collection. Therefore, it would be desirable to establish a simple and reliable test for estimating 24UNa excretion.

Dietary recall is known to under-report nutrient intake, and so gives less accurate estimates than those based on urinary data $[14,15]$. Several techniques have been proposed to replace the 24-hr urine test. Trials based on casual urine samples, also known as spot urine, have been carried out. Tanaka's equation and the Korean formula have been suggested for estimating

\footnotetext{
§Corresponding Author: Sang Youb Han, Tel. 82-31-910-7201, Fax. 82-31-910-7219, Email. hansy@paik.ac.kr

Received: April 17, 2019, Revised: May 19, 2019, Accepted: August 13, 2019

* These two authors contributed equally to this study.

This is an Open Access article distributed under the terms of the Creative Commons Attribution Non-Commercial License (http://creativecommons.org/licenses/by-nc/3.0/) which permits unrestricted non-commercial use, distribution, and reproduction in any medium, provided the original work is properly cited.
} 
24UNa $[16,17]$. These two formulas identify patients who consume $>100 \mathrm{mEq}$ of $\mathrm{Na}$ per day with sensitivities $>80 \%$ [17]. Urinary $\mathrm{Na}$ /creatinine $(\mathrm{Na} / \mathrm{Cr}$ ) and $\mathrm{Na} /$ potassium $(\mathrm{Na} / \mathrm{K})$ ratios have also been suggested for estimating daily sodium intake or salt loading, although the former needs correction for urinary $\mathrm{Cr}$ excretion $[10,18]$.

The spot urine test suffers disadvantages because the results vary depending on diet and inspection time. Mann et al. [18] reported that the $\mathrm{Na} / \mathrm{Cr}$ ratio of late afternoon/early evening urine samples obtained near the midpoint of the 24-hr collection period was strongly correlated with actual 24UNa excretion. However, $57 \%$ of the participants examined were taking diuretics, which could have confounded the results [18]. No consensus has yet been reached on the best method for estimating daily sodium intake. In this study, urine samples were collected at every episode of urination for 24 hours. We measured $\mathrm{Na}$ and other electrolytes in each urine sample and examined any correlations that could represent $24 \mathrm{UNa}$.

\section{SUBJECTS AND METHODS}

\section{Subjects}

Fifteen healthy men between 20 and 60 years old were enrolled in 3 teaching hospitals: Inje University Ilsan-Paik Hospital, Hanyang University Guri Hospital, and Yonsei University Gangnam Severance Hospital. None of the participants was taking any medication or had any chronic medical diseases such as hypertension, diabetes, hepatitis, inflammatory diseases, and malignancy. The study protocol was approved by the institutional review boards of Inje University, Ilsan-Paik Hospital (IB-0911-048), Hanyang University Guri Hospital (GURI 2009-11-005), and Yonsei University Gangnam Severance Hospital (3-2009-0178) and written informed consent was obtained before the screening procedure.

\section{Processing and measurement of urinary parameters}

On the first day, the fifteen men were offered 3 meals containing a total of $9-10 \mathrm{~g}$ of salt, prepared under the supervision of nutritionists working for each hospital. Ten of them consumed all the $10 \mathrm{~g}$ salt on the first day completely. The other 5 participants did not eat the full meals completely and their total intake was evaluated by the hospital nutritionist and the amount of salt consumed was calculated. All the participants had only 3 meals and drank as much water as they wanted over the 24-hr period. Twenty-four-hr urine was collected from the second-void urine of the first day to the first-void urine of the second day. The urine samples were collected by the participants, who were provided with graduated cylinders to measure the volume of each sample on site. All the samples were transported in conical centrifuge tubes and kept in a -70 degree refrigerator for further analysis.

24UNa excretion was estimated using Tanaka's equations and the Korean formulas for predicting 24-hr urinary $\mathrm{Cr}$ in Koreans: Tanaka's equations are: 1) Estimated 24UNa_Tanaka (mEq/day) $=21.98 \times(\{$ spot urine $\mathrm{Na}(\mathrm{mEq} / \mathrm{L}) /[10 \times$ spot urine $\mathrm{Cr}(\mathrm{mg} / \mathrm{dL})]\}$ $\times$ predicted value of $24-\mathrm{hr}$ urinary $\mathrm{Cr}(\mathrm{PRCr})$ _Tanaka $)^{0.392}$ [16], 2) $\mathrm{PRCr}$ Tanaka $(\mathrm{mg} /$ day $)=-2.04 \times$ age $(\mathrm{yr})+14.89 \times$ weight $(\mathrm{kg})$ $+16.14 \times$ height $(\mathrm{cm})-2244.45$ [16]. The Korean formulas are: 1) Estimated $24 \mathrm{UNa}$ KKorea $(\mathrm{mEq} /$ day $)=28.985 \times($ spot urine $\mathrm{Na}$
$(\mathrm{mEq} / \mathrm{L}) /[10 \times$ spot urine $\mathrm{Cr}(\mathrm{mg} / \mathrm{dL})]\} \times \mathrm{PRCr}$ KKorea $)^{0.346}[17]$, 2) $\mathrm{PRCr}$ Korea $(\mathrm{mg} /$ day $)=-7.428 \times$ age $(\mathrm{yr})+10.372 \times$ weight $(\mathrm{kg})$ $+15.631 \times$ height $(\mathrm{cm})-1,234.785$ [17].

Urinary $\mathrm{Na}, \mathrm{K}$, chloride $(\mathrm{Cl})$, urea nitrogen $(\mathrm{UN}), \mathrm{Cr}$, specific gravity (SG) and osmolality (Osm) were measured from each spot urine sample. All biochemical measurements were performed in a central laboratory (Green Cross Laboratories, Republic of Korea). Urinary $\mathrm{Na}, \mathrm{K}$ and $\mathrm{Cl}$ were measured with ion selective electrodes using an automatic analyzer (ADVIA 1650, Siemens, USA). Urinary UN and $\mathrm{Cr}$ were measured with the same automatic analyzer by the kinetic UV assay and the Jaffe method, respectively. Urinary SG was measured by reflection refractometry using a URISYS 2400 (Roche, Japan). Urinary Osm was measured with a freezing point osmometer (Fiske one-ten, Fiske, USA).

\section{Relationship between 24UNa and spot urine $\mathrm{Na}$}

We calculated the ratios of urinary $\mathrm{Na}$ to other urinary parameters, and identified any correlations with total measured 24UNa. Three sets of urine samples were compared: the first-void morning urine of the second day, the second-void urine of the first day, and all random urine samples from each participant. Urinary $\mathrm{Na}$ was adjusted for urinary $\mathrm{K}, \mathrm{Cr}, \mathrm{Cl}$, UN, SG and Osm: urinary $\mathrm{Na} / \mathrm{K}$, urinary $\mathrm{Na} / \mathrm{Cr}$, urinary $\mathrm{Na} / \mathrm{Cl}$, urinary $\mathrm{Na} / \mathrm{UN}$, urinary $\mathrm{Na} / \mathrm{SG}$ and urinary $\mathrm{Na} / \mathrm{Osm}$. The 24UNa level was estimated using Tanaka's equation and the Korean formula based on the results for all spot urine samples. Adjusted and estimated values were compared to the measured $24 \mathrm{UNa}$, and their correlations were analyzed. The coefficients of intra-personal variation for each modified variable were also calculated to determine the variability of the methods.

\section{Data analysis}

Data are presented as means \pm standard deviations (SD). Associations between measured 24UNa and demographic factors, spot urine $\mathrm{Na}$ and other urinary parameters were analyzed by the Pearson's correlation method. Intra-personal coefficients of variation were calculated as the ratio of the SD to the mean of each value and expressed as a percentage. Data were analyzed with the SPSS 15.0 program (SPSS Inc, Chicago, IL, USA).

\section{RESULTS}

Clinical characteristics of the subjects

The basic characteristics of the fifteen men (mean $32.7 \pm 6.5$ years) are summarized in Table 1 . Average dietary salt intake was $9.2 \pm 1.2 \mathrm{~g} /$ day (range, 6.3-10 g/day) and average voiding frequency was $5.9 \pm 1.9$ voids/day. The total number of random urine samples was 88 (Table 2). The average voiding times of the second-void urine of the first day and the first-void urine of the second day were 11:54 \pm 1:42 AM (median, 11:30 AM; range, 10:15 AM-16:10 PM) and 7:09 \pm 1:00 AM (median, 7:17 $\mathrm{AM}$; range, 5:55 AM-10:00 AM), respectively. The mean 24-hr urinary creatinine per kilogram of body weight was $21.7 \pm 4.9$ $\mathrm{mg} / \mathrm{kg}$. The average 24-hr urine volume was $1,403 \pm 475 \mathrm{~mL}$ and the mean measured 24UNa was $143.9 \pm 42.1 \mathrm{mEq}$ (range, 87.1-239.4 mEq). The measured 24UNa of 13 of the participants was $>100 \mathrm{mEq}$. The mean urinary $\mathrm{Na} / \mathrm{K}$ in all collected urine samples was $3.0 \pm 0.89$ (range, 1.29-4.64). Measured 24UNa was 
Table 1. Clinical characteristics of the subjects.

\begin{tabular}{lr}
\hline \multicolumn{1}{c}{ Variable } & $(\mathrm{n}=15)$ \\
\hline Age (yrs) & $32.7 \pm 6.5$ \\
Weight $(\mathrm{kg})$ & $72.2 \pm 7.6$ \\
Height $(\mathrm{cm})$ & $172.7 \pm 5.9$ \\
Body mass index $\left(\mathrm{kg} / \mathrm{m}^{2}\right)$ & $24.3 \pm 2.7$ \\
Dietary salt intake $(\mathrm{g} /$ day) & $9.2 \pm 1.2$ \\
Voiding frequency (voids/day) & $5.9 \pm 2.0$ \\
Voiding time & \\
Second-void, first day (hh:mm) & $11: 54 \pm 1: 42$ \\
First-void, second day (hh:mm) & $07: 09 \pm 1: 00$ \\
24-hour urine & \\
Volume (mL/day) & $1,403 \pm 475$ \\
Creatinine (mg/day) & $1,572 \pm 400$ \\
Na (mEq/day) & $143.9 \pm 42.1$ \\
$\mathrm{~K}$ (mEq/day) & $51.0 \pm 16.8$ \\
Na/K & $3.0 \pm 0.89$ \\
$\mathrm{Cl}$ (mEq/day) & $160.1 \pm 49.1$ \\
Urea nitrogen (mg/day) & $10,779 \pm 2,488$ \\
Osmolality (mOsm/day) & $818.3 \pm 176.7$ \\
\hline
\end{tabular}

Values are presented as means \pm SDs.

Abbreviations: $\mathrm{Na}$, sodium; $\mathrm{K}$, potassium; $\mathrm{Cl}$, chloride.

significantly correlated with estimated 24UNa using Tanaka's equation $(r=0.673, P<0.01)$ and the Korean formula $(r=0.612$, $P<0.05)$ in all collected urine samples.

Correlations between measured 24UNa, and demographic factors, urinary parameters, and estimated $24 \mathrm{UNa}$ in all spot urine samples
The mean urinary $\mathrm{Na} / \mathrm{K}$ in all spot urine samples was 2.95 \pm 1.29 (range, 0.43-6.04). Measured 24UNa was significantly correlated with urinary $\mathrm{Na} / \mathrm{UN}(r=0.560, P<0.01)$, urinary $\mathrm{Na}$ Osm $(r=0.510, P<0.01)$, urinary $\mathrm{Na} / \mathrm{Cr}(r=0.392, P<0.01)$, urinary $\mathrm{Na} / \mathrm{K}(r=0.290, P<0.01)$, estimated 24UNa using Tanaka's equation $(r=0.452, P<0.01)$ and the Korean formula $(r=0.414$, $P<0.01)$, age $(r=0.548, P<0.01)$, weight $(r=0.497, P<0.01)$, and height $(r=0.393, P<0.01)$ for all random urine samples (Table 2).

Correlations between measured 24UNa, and demographic factors, urinary parameters, and estimated $24 \mathrm{UNa}$ in the $2^{\text {nd }}$ urine of the $1^{\text {st }}$ day

The mean urinary $\mathrm{Na} / \mathrm{K}$ in the second-void urine of the first day was $3.08 \pm 1.35$ (range, 1.45-5.91). Estimated 24UNa from the second-void spot urine of the first day tended to be more tightly correlated with measured $24 \mathrm{UNa}$ than the corresponding values from the other two spot urine samples, i.e., the first-void urine of the second day and all random urines. The following most significant correlations were seen for the second-void urine of the first day: urinary $\mathrm{Na} / \mathrm{K}(\mathrm{r}=0.647, P<0.01)$, urinary $\mathrm{Na} / \mathrm{Cr}(\mathrm{r}=0.558, P<0.05)$, and estimated 24UNa using Tanaka's equation $(r=0.616, P<0.05)$ and Korean formula $(r=0.588$, $P<0.05$ ) (Table 2, Fig. 1, Fig. 2).

Correlations between measured 24UNa, and demographic factors, urinary parameters, and estimated $24 \mathrm{UNa}$ in the $1^{\text {st }}$ urine of the $2^{\text {nd }}$ day

The mean urinary $\mathrm{Na} / \mathrm{K}$ in the first-void urine of the second day was $2.24 \pm 1.47$ (range, 0.47-5.28). The first-void morning urine of the second day gave unexpectedly poor correlations

Table 2. Pearson's correlation coefficients ( $r$ ) between measured 24UNa and demographic factors and urinary parameters according to time of urine sampling

\begin{tabular}{|c|c|c|c|c|c|c|c|c|c|c|c|}
\hline \multirow{2}{*}{ Urine sample time } & \multirow{2}{*}{ Cases (n) } & \multicolumn{4}{|c|}{ Demographic factor } & \multicolumn{6}{|c|}{ Urinary parameter } \\
\hline & & Age & Weight & Height & BMI & $\mathrm{Na} / \mathrm{K}$ & $\mathrm{Na} / \mathrm{Cr}$ & $\mathrm{Na} / \mathrm{Cl}$ & $\mathrm{Na} / \mathrm{UN}$ & $\mathrm{Na} / \mathrm{SG}$ & $\mathrm{Na} / \mathrm{Osm}$ \\
\hline Random & 88 & $0.548^{* *}$ & $0.497^{* *}$ & $0.393^{* *}$ & 0.206 & $0.290^{* *}$ & $0.392^{* *}$ & 0.125 & $0.560^{* *}$ & 0.191 & $0.510^{* *}$ \\
\hline $2^{\text {nd }}$ urine on $1^{\text {st }}$ day & 15 & & & & & $0.647^{* *}$ & $0.558^{*}$ & 0.268 & 0.462 & -0.266 & 0.408 \\
\hline $1^{\text {st }}$ urine on $2^{\text {nd }}$ day & 15 & & & & & -0.030 & 0.203 & -0.090 & 0.322 & $0.596^{*}$ & 0.308 \\
\hline
\end{tabular}

Significant at ${ }^{*} P<0.05$ and ${ }^{* *} P<0.01$

Abbreviations: 24UNa, 24-hour urinary sodium; BMl, body mass index; Na, sodium; K, potassium; Cr, creatinine; Cl, chloride; UN, urea nitrogen; SG, specific gravity; Osm, osmolality.
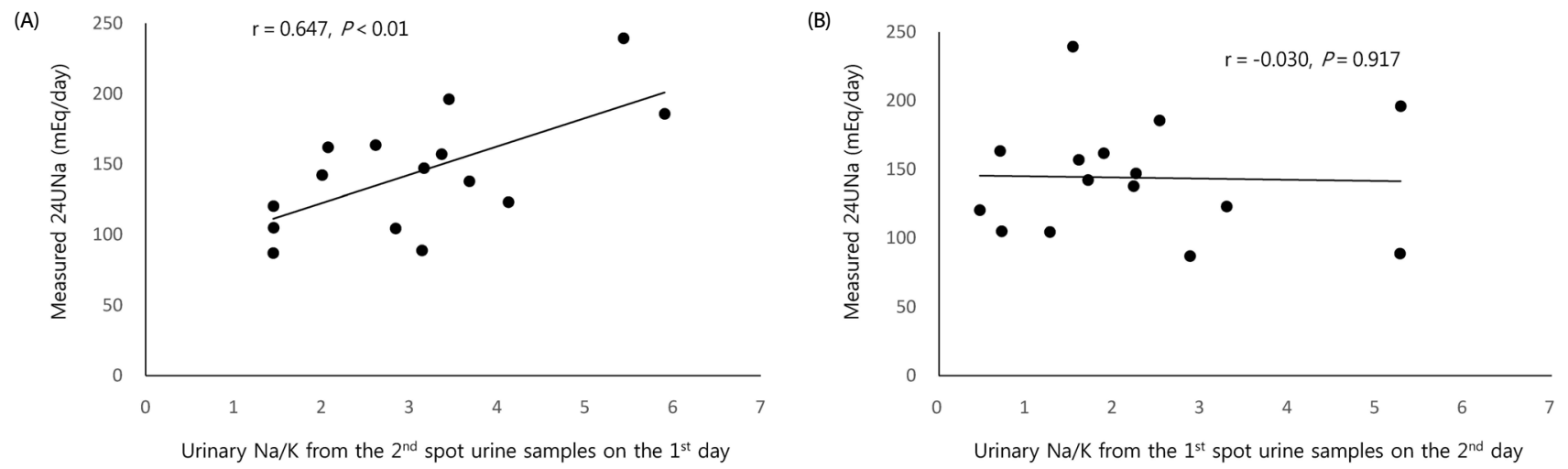

Fig. 1. Correlations between measured $24 \mathrm{UNa}$, and urinary $\mathrm{Na} / \mathrm{K}$ in the second-void spot urine samples taken on the first day (A) and in the first-void spot urine samples taken on the second day (B). Pearson's correlation coefficients and $P$-values are shown for each plot. Each line represents the linear regression for the plotted plot. $24 \mathrm{UNa}$, 24-hour urinary sodium; Na, sodium; K, potassium. 


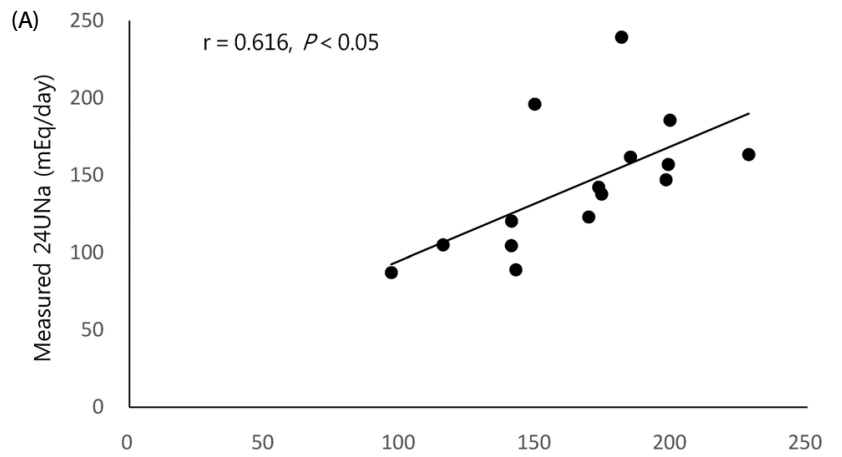

Estimated 24UNa from the $2^{\text {nd }}$ spot urine samples on the $1^{\text {st }}$ day using Tanaka's equation ( $\mathrm{mEq} /$ day)

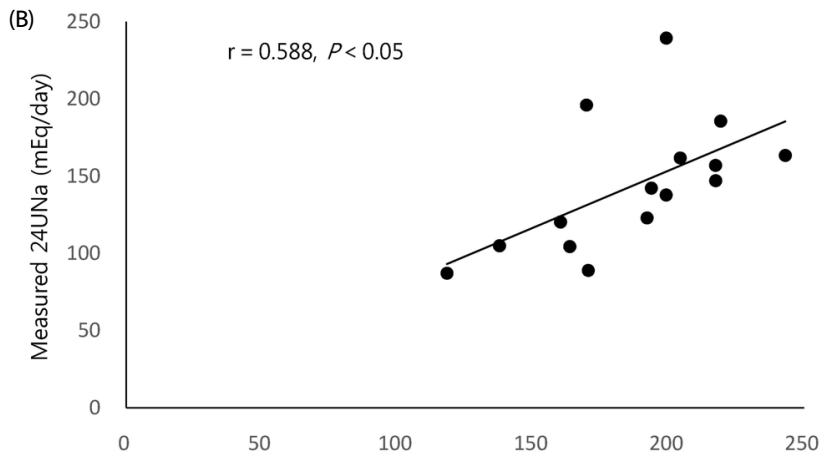

Estimated 24UNa from the $2^{\text {nd }}$ spot urine samples on the $1^{\text {st }}$ day using the Korean formula ( $\mathrm{mEq} /$ day)

Fig. 2. Correlations between measured $24 \mathrm{UNa}$ and $24 \mathrm{UNa}$ estimated from Tanaka's equation (A) and the Korean formula (B) in the second-void spot urine samples taken on the first day. Pearson's correlation coefficients and P-values are shown for each plot. Each line represents the linear regression for the plotted data. 24UNa: 24-hour urinary sodium.

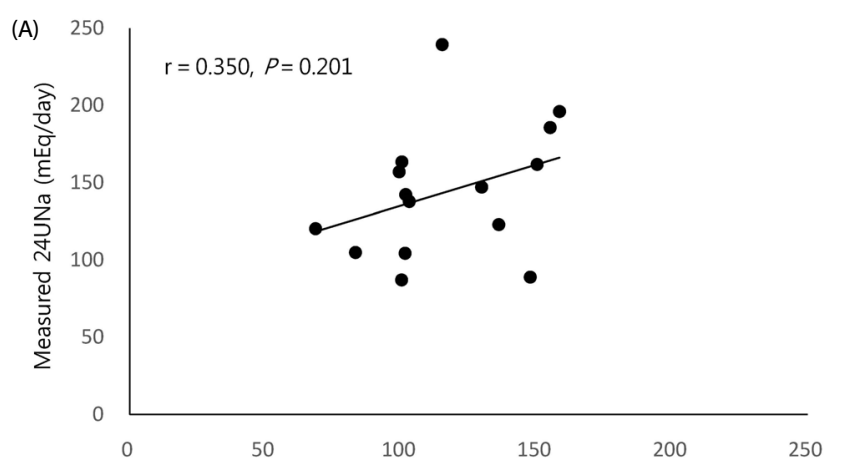

Estimated 24UNa from the $1^{\text {st }}$ spot urine samples on the $2^{\text {nd }}$ day using Tanaka's equation (mEq/day)

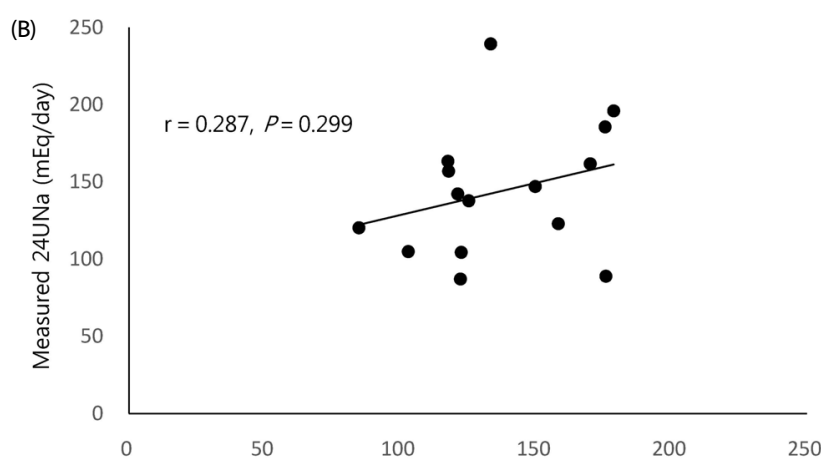

Estimated $24 \mathrm{UNa}$ from the $1^{\text {st }}$ spot urine samples on the $2^{\text {nd }}$ day using the Korean formula ( $\mathrm{mEq} /$ day)

Fig. 3. Correlations between measured $24 \mathrm{UNa}$ and $24 \mathrm{UNa}$ estimated from Tanaka's equation (A) and the Korean formula (B) in the first-void spot urine samples taken on the second day. Pearson's correlation coefficients and $P$-values are shown for each plot. Each line represents the linear regression for the plotted plot. 24UNa: 24-hour urinary sodium.

Table 3. Coefficients of intra-personal variation for urinary parameters and estimated $24 \mathrm{UNa}$ in all random urine samples ( $\mathrm{n}=88$ ) from the 15 participants

\begin{tabular}{|c|c|c|c|c|c|c|c|c|}
\hline & \multicolumn{6}{|c|}{ Urinary parameter } & \multicolumn{2}{|c|}{ Estimated $24 \mathrm{UNa}$} \\
\hline & $\mathrm{Na} / \mathrm{K}$ & $\mathrm{Na} / \mathrm{Cr}$ & $\mathrm{Na} / \mathrm{Cl}$ & $\mathrm{Na} / \mathrm{UN}$ & $\mathrm{Na} / \mathrm{SG}$ & $\mathrm{Na} / \mathrm{Osm}$ & Tanaka's Equation $^{\dagger}$ & Korean formula \\
\hline CV\% & $34.6 \pm 10.1$ & $39.9 \pm 15.2$ & $14.1 \pm 8.1$ & $33.0 \pm 10.3$ & $38.9 \pm 18.5$ & $24.2 \pm 9.0$ & $17.8 \pm 7.5$ & $15.9 \pm 6.8$ \\
\hline
\end{tabular}

†Tanaka's equations [16]:

1) Estimated 24UNa_Tanaka $(\mathrm{mEq} /$ day $)=21.98 \times($ spot urine $\mathrm{Na}(\mathrm{mEq} / \mathrm{L}) /[10 \times$ spot urine $\mathrm{Cr}(\mathrm{mg} / \mathrm{dL})]\} \times \mathrm{PRCr}$ _Tanaka $)^{0.392}$

2) PRCr_Tanaka $(\mathrm{mg} /$ day $)=-2.04 \times$ age $(\mathrm{yr})+14.89 \times$ weight $(\mathrm{kg})+16.14 \times$ height $(\mathrm{cm})-2,244.45$

$\ddagger$ Korean formulas [17]:

1) Estimated 24UNa_Korea $(\mathrm{mEq} /$ day $)=28.985 \times(\{\text { spot urine } \mathrm{Na}(\mathrm{mEq} / \mathrm{L}) /[10 \times \text { spot urine } \mathrm{Cr}(\mathrm{mg} / \mathrm{dL})]\} \times \mathrm{PRCr} \text { KKorea })^{0.346}$

2) PRCr_Korea $(\mathrm{mg} /$ day $)=-7.428 \times$ age $(\mathrm{yr})+10.372 \times$ weight $(\mathrm{kg})+15.631 \times$ height $(\mathrm{cm})-1,234.785$

Abbreviations: 24UNa, 24-hour urinary sodium; CV\%, percent coefficient of intrapersonal variation; $\mathrm{Na}$, sodium; $\mathrm{K}$, potassium; Cr, creatinine; Cl, chloride; UN, urea nitrogen; SG, specific gravity; Osm, osmolality; predicted value of 24-hour urinary $\mathrm{Cr}, \mathrm{PRCr}$.

compared with all collected urine, all random urine and the second-void spot urine of the first day. Only urinary $\mathrm{Na} / \mathrm{SG}$ $(r=0.596, P<0.05)$ was correlated with measured 24UNa (Table 2, Fig. 1, Fig. 3).

\section{Intra-personal variability of urinary parameters and estimated} $24 \mathrm{UNa}$

The percent coefficients of intra-personal variation (CV\%) of all urinary parameters except $\mathrm{Na} / \mathrm{Cl}$ were large compared to those of estimated 24UNa. The CV percentages for urinary $\mathrm{Na} / \mathrm{K}$, urinary $\mathrm{Na} / \mathrm{Cr}$ and urinary $\mathrm{Na} / \mathrm{UN}$ were $34.6 \pm 10.1 \%, 39.9 \pm$ $15.2 \%$ and $33.0 \pm 10.3 \%$, respectively, and those for estimated 24UNa using Tanaka's equation and the Korean formula were relatively small: $17.8 \pm 7.5 \%$ and $15.9 \pm 6.8 \%$, respectively (Table 3 ).

\section{DISCUSSION}

The urinary $\mathrm{Na} / \mathrm{K}$ ratio of the second-void urine taken around midday of the first day displayed the most significant correlation with measured $24 \mathrm{UNa}$ in fifteen adults that consumed an 
average of $9.2 \mathrm{~g}$ salt in one 24-hr session. Urinary $\mathrm{Na} / \mathrm{Cr}$, and estimated 24UNa by Tanaka's equation and the Korean formula were also significantly correlated with measured 24UNa. However, first-void morning urine did not yield good correlations except with urinary $\mathrm{Na} / \mathrm{SG}$.

The spot urine $\mathrm{Na} / \mathrm{K}$ ratio is a useful estimate of the 24-hr urine $\mathrm{Na} / \mathrm{K}$ ratio and has been suggested as an alternative method for assessing salt loading $[19,20]$, in both hypertensive patients and healthy individuals [21,22]. Recent epidemiological studies have reported that the $\mathrm{Na} / \mathrm{K}$ ratios in first-void morning urine and 24-hr urine are correlated with blood pressure [23-25]. Observational studies have also shown that the urinary $\mathrm{Na} / \mathrm{K}$ ratio is more strongly associated with increased blood pressure and subsequent cardiovascular disease than either $\mathrm{Na}$ or $\mathrm{K}$ alone $[26,27]$. The correlation between the $\mathrm{Na} / \mathrm{K}$ ratios for casual urine and 7-day 24-hr urine reached 0.80 for mean 4-day values and 0.87 for mean 7-day values [22]. In the current study, the urinary $\mathrm{Na} / \mathrm{K}$ ratio of the second-void urine was also strongly correlated with measured 24UNa $(r=0.647, P<0.01)$.

A further advantage of the urinary $\mathrm{Na} / \mathrm{K}$ ratio was to determine whether patients consumed a low salt diet or not. If the urinary $\mathrm{Na} / \mathrm{K}$ ratio was equal to or higher than 1 in patients with liver cirrhosis with ascites, the probability that random spot urine $\mathrm{Na}$ concentration was over $78 \mathrm{mEq}$ was 90 to 95 percent [28]. In our study, the minimum $24 \mathrm{UNa}$ was $87.1 \mathrm{mEq}$ and the minimum urinary $\mathrm{Na} / \mathrm{K}$ of the second-void urine of the first day was 1.45 . Although we performed this trial with healthy people, the result corresponded with a previous report on hypertensive patients [28]. Based on their own studies for hypertensive and healthy normotensive subjects, Iwahori et al. [21,22,29] have suggested that the urinary $\mathrm{Na} / \mathrm{K}$ ratio could be a robust monitoring tool for $\mathrm{Na}$ reduction and $\mathrm{K}$ increase in the normal population, as well as for patients during treatment.

Although first-void morning urine is widely used for measuring microalbuminuria and proteinuria, its accuracy for estimating urinary Na remains unconfirmed. Collecting first-void morning urine is also impractical due to difficulties associated with having just woken up. Mann et al. [18] reported that the urinary $\mathrm{Na} / \mathrm{Cr}$ ratio in the late afternoon was strongly correlated with measured 24UNa. In another study, however, evening urine samples showed larger within-person variation in urinary $\mathrm{Na}$ and $\mathrm{K}$ excretion, along with day-to-day and diurnal variation [30]. Katama et al. [31] also reported that night-time urinary $\mathrm{Na}$ reflected $24 \mathrm{UNa}$ with a correlation of $78 \%$. In our own present study, the intra-personal variability of each parameter was relatively high due to the great variability of first-void morning urine compared to those of other times. Because of this high variability and the difficulty in collecting first-void morning urine, second-void urine may be better for estimating 24UNa. Authors could not explain why estimating 24-UNa from the first-void urine samples did not show good correlation with measured 24UNa. It could be hypothesized that the second-void urine samples are likely to be a better estimation for the pulsatile circadian excretion of urine $\mathrm{Na}$ after dietary $\mathrm{Na}$ intake than the first morning fasting urine samples.

The strength of our study is that urinary $\mathrm{Na}$ and other urinary parameters were measured in every void of urine over 24 hours, along with $24-\mathrm{hr}$ urine obtained by summing all voids.
Furthermore, according to the Korea National Health and Nutrition Examination Survey (KNHANES VII-1) results for 2016, the average daily salt intake of Korean adults aged 19 years or older was $9.8 \mathrm{~g}$ [32]. The Korean population has high dietary salt consumption, and the participants in the present study consumed $9.2 \pm 1.2 \mathrm{~g}$ of salt a day, which indicates that our results could be applicable to the entire adult population of Korea.

This study has the following four limitations. First is the very small sample size. Second, only healthy individuals were enrolled, so it is uncertain whether the results can be applied to patients with chronic diseases such as chronic kidney disease and congestive heart failure [33]. Since renal excretion and reabsorption of sodium can be affected by chronic diseases and medication $[33,34]$ the challenge to clarify the scope of application remains. Third, there were large variations in $24 \mathrm{UNa}$, even though a comparable amount of salt was provided to all participants for this data. Among fifteen participants, ten consumed $10 \mathrm{~g}$ salt a day and the other five consumed 6-9 g salt a day. Twenty-fourhour (hr) urinary sodium may be affected by the sodium intake over the previous several days, which could induce the variation of the 24UNa in this study. Fourth, two formulas using a spot urine sample test for estimating 24UNa did not identify high $\mathrm{Na}$ consumption in $14 \%$ of cases [17]. However, this problem is not specific to our present study, although all previous studies using spot urine may have the same flaw.

In conclusion, despite these limitations, the strong correlation between urinary $\mathrm{Na} / \mathrm{K}$ in the second-void urine around midday and 24UNa suggests that this test could be useful as a substitute for $24 \mathrm{UNa}$, and for assessing compliance with dietary salt restrictions in population surveillance and in outpatient settings.

\section{CONFLICT OF INTEREST}

The authors declare no potential conflicts of interests.

\section{ACKNOWLEDGMENTS}

We thank the clinical dietary departments of the participating institutions for their support.

\section{ORCID}

Jung Gon Kim: https://orcid.org/0000-0002-3661-4974

Sang-Woong Han: https://orcid.org/0000-0003-3658-7248

Joo Hark Yi: https://orcid.org/0000-0002-9931-8937

Hyeong Cheon Park: https://orcid.org/0000-0002-1550-0812

Sang Youb Han: https://orcid.org/0000-0003-3312-0597

\section{REFERENCES}

1. Aburto NJ, Ziolkovska A, Hooper L, Elliott P, Cappuccio FP, Meerpoh JJ. Effect of lower sodium intake on health: systematic review and meta-analyses. BMJ 2013;346:f1326.

2. Jones-Burton C, Mishra SI, Fink JC, Brown J, Gossa W, Bakris GL, Weir MR. An in-depth review of the evidence linking dietary salt intake and progression of chronic kidney disease. Am J Nephrol 2006;26:268-75. 
3. Swift PA, Markandu ND, Sagnella GA, He FJ, MacGregor GA. Modest salt reduction reduces blood pressure and urine protein excretion in black hypertensives: a randomized control trial. Hypertension 2005;46:308-12.

4. Intersalt Cooperative Research Group. Intersalt: an international study of electrolyte excretion and blood pressure. Results for 24 hour urinary sodium and potassium excretion. BMJ 1988;297:319-28.

5. Ha SK. Dietary salt intake and hypertension. Electrolyte Blood Press 2014;12:7-18

6. McLean RM. Measuring population sodium intake: a review of methods. Nutrients 2014;6:4651-62.

7. Brown IJ, Dyer AR, Chan Q, Cogswell ME, Ueshima H, Stamler J, Elliott P; INTERSALT Co-Operative Research Group. Estimating 24-hour urinary sodium excretion from casual urinary sodium concentrations in Western populations: the INTERSALT study. Am J Epidemiol 2013;177:1180-92.

8. Cogswell ME, Loria CM, Terry AL, Zhao L, Wang CY, Chen TC, Wright JD, Pfeiffer CM, Merritt R, Moy CS, Appel LJ. Estimated 24-hour urinary sodium and potassium excretion in US adults. JAMA 2018;319:1209-20.

9. Komiyama $Y$, Kurosaki $M$, Nakanishi $H$, Takahashi $Y$, Itakura J, Yasui Y, Tamaki N, Takada H, Higuchi M, Gotou T, Kubota Y, Takaura K, Hayashi T, Oh W, Okada M, Enomoto N, Izumi N. Prediction of diuretic response to tolvaptan by a simple, readily available spot urine $\mathrm{Na} / \mathrm{K}$ ratio. PLoS One 2017;12:e0174649.

10. El-Bokl MA, Senousy BE, El-Karmouty KZ, Mohammed IK, Mohammed SM, Shabana SS, Shalaby $\mathrm{H}$. Spot urinary sodium for assessing dietary sodium restriction in cirrhotic ascites. World J Gastroenterol 2009;15:3631-5.

11. Colin-Ramirez E, Arcand J, Ezekowitz JA. Estimates of dietary sodium consumption in patients with chronic heart failure. J Card Fail 2015;21:981-8.

12. Mills KT, Chen J, Yang W, Appel $\sqcup$, Kusek JW, Alper A, Delafontaine P, Keane MG, Mohler E, Ojo A, Rahman M, Ricardo AC, Soliman EZ, Steigerwalt S, Townsend R, He J; Chronic Renal Insufficiency Cohort (CRIC) Study Investigators. Sodium excretion and the risk of cardiovascular disease in patients with chronic kidney disease. JAMA 2016;315:2200-10.

13. Boudville N, Ward S, Benaroia M, House AA. Increased sodium intake correlates with greater use of antihypertensive agents by subjects with chronic kidney disease. Am J Hypertens 2005;18:1300-5.

14. Livingstone MB, Prentice AM, Strain JJ, Coward WA, Black AE, Barker ME, McKenna PG, Whitehead RG. Accuracy of weighed dietary records in studies of diet and health. BMJ 1990;300:708-12.

15. Johnson RK, Goran Ml, Poehlman ET. Correlates of over- and underreporting of energy intake in healthy older men and women. Am J Clin Nutr 1994;59:1286-90.

16. Tanaka T, Okamura $T$, Miura K, Kadowaki T, Ueshima H, Nakagawa $\mathrm{H}$, Hashimoto T. A simple method to estimate populational 24- $\mathrm{h}$ urinary sodium and potassium excretion using a casual urine specimen. J Hum Hypertens 2002;16:97-103.

17. Koo HS, Kim YC, Ahn SY, Oh SW, Kim S, Chin HJ, Park JH. Estimating 24-hour urine sodium level with spot urine sodium and creatinine. J Korean Med Sci 2014;29 Suppl 2:S97-102.

18. Mann SJ, Gerber LM. Estimation of 24-hour sodium excretion from spot urine samples. J Clin Hypertens (Greenwich) 2010;12:174-80.

19. Iwahori T, Miura K, Ueshima H, Chan Q, Dyer AR, Elliott P, Stamler J; INTERSALT Research Group. Estimating 24-h urinary sodium/ potassium ratio from casual ('spot') urinary sodium/potassium ratio: the INTERSALT Study. Int J Epidemiol 2017;46:1564-72.

20. Tabara Y, Takahashi Y, Kumagai K, Setoh K, Kawaguchi T, Takahashi M, Muraoka Y, Tsujikawa A, Gotoh N, Terao C, Yamada R, Kosugi S, Sekine A, Yoshimura N, Nakayama T, Matsuda F; Nagahama study group. Descriptive epidemiology of spot urine sodium-to-potassium ratio clarified close relationship with blood pressure level: the Nagahama study. J Hypertens 2015;33:2407-13.

21. Iwahori $\mathrm{T}$, Ueshima $\mathrm{H}$, Miyagawa $\mathrm{N}$, Ohgami $\mathrm{N}$, Yamashita $\mathrm{H}$, Ohkubo T, Murakami $Y$, Shiga T, Miura K. Six random specimens of daytime casual urine on different days are sufficient to estimate daily sodium/potassium ratio in comparison to 7-day 24-h urine collections. Hypertens Res 2014;37:765-71.

22. Iwahori T, Ueshima H, Torii S, Saito Y, Fujiyoshi A, Ohkubo T, Miura $\mathrm{K}$. Four to seven random casual urine specimens are sufficient to estimate 24-h urinary sodium/potassium ratio in individuals with high blood pressure. J Hum Hypertens 2016;30:328-34.

23. Stamler J, Rose G, Stamler R, Elliott $P$, Dyer A, Marmot M. INTERSALT study findings. Public health and medical care implications. Hypertension 1989;14:570-7.

24. Huggins $C E$, O'Reilly S, Brinkman M, Hodge A, Giles GG, English DR, Nowson CA. Relationship of urinary sodium and sodium-topotassium ratio to blood pressure in older adults in Australia. Med J Aust 2011;195:128-32.

25. Hedayati SS, Minhajuddin AT, ljaz A, Moe OW, Elsayed EF, Reilly $\mathrm{RF}$, Huang CL. Association of urinary sodium/potassium ratio with blood pressure: sex and racial differences. Clin J Am Soc Nephrol 2012;7:315-22.

26. Perez V, Chang ET. Sodium-to-potassium ratio and blood pressure, hypertension, and related factors. Adv Nutr 2014;5:712-41.

27. Cook NR, Obarzanek E, Cutler JA, Buring JE, Rexrode KM, Kumanyika SK, Appel U, Whelton PK; Trials of Hypertension Prevention Collaborative Research Group. Joint effects of sodium and potassium intake on subsequent cardiovascular disease: the Trials of Hypertension Prevention follow-up study. Arch Intern Med 2009;169:32-40

28. da Silva OM, Thiele GB, Fayad L, Lazzarotto C, Dantas-Corrêa EB, de Lucca Schiavon L, Narciso-Schiavon JL. Comparative study of spot urine $\mathrm{Na} / \mathrm{K}$ ratio and 24-hour urine sodium in natriuresis evaluation of cirrhotic patients with ascites. GE J Port Gastrenterol 2014;21:15-20.

29. Iwahori T, Miura K, Ueshima H. Time to consider use of the sodium-to-potassium ratio for practical sodium reduction and potassium increase. Nutrients 2017;9:700

30. Wang $C Y$, Cogswell ME, Loria CM, Chen TC, Pfeiffer CM, Swanson CA, Caldwell KL, Perrine CG, Carriquiry AL, Liu K, Sempos CT, Gillespie CD, Burt VL. Urinary excretion of sodium, potassium, and chloride, but not iodine, varies by timing of collection in a 24-hour calibration study. J Nutr 2013;143:1276-82.

31. Kamata K, Tochikubo O. Estimation of 24-h urinary sodium excretion using lean body mass and overnight urine collected by a pipe-sampling method. J Hypertens 2002;20:2191-7.

32. Ministry of Health and Welfare, Korea Centers for Disease Control and Prevention. Korea Health Statistics 2016: Korea National Health and Nutrition Examination Survey (KNHANES VII-1). Cheongju: Korea Centers for Disease Control and Prevention; 2017.

33. Dougher $C E$, Rifkin DE, Anderson CA, Smits G, Persky MS, Block $\mathrm{GA}, \mathrm{Ix} \mathrm{JH}$. Spot urine sodium measurements do not accurately 
estimate dietary sodium intake in chronic kidney disease. Am J Clin Nutr 2016;104:298-305.

34. Arcand J, Floras JS, Azevedo E, Mak S, Newton GE, Allard JP.
Evaluation of 2 methods for sodium intake assessment in cardiac patients with and without heart failure: the confounding effect of loop diuretics. Am J Clin Nutr 2011;93:535-41. 